\title{
Avaliação de Cinco Híbridos de Milho (Zea mays, L.) em Diferentes Estádios de Maturação. 1. Produtividade, Características Morfológicas e Correlações ${ }^{1,2}$
}

\section{Juliano Ricardo Fontanini Beleze 3 , Lúcia Maria Zeoula4, Ulysses Cecato ${ }^{4}$, Paulo Henrique Moura Dian ${ }^{5}$, Elias Nunes Martins ${ }^{4}$, Alencariano José da Silva Falcão ${ }^{6}$}

\begin{abstract}
RESUMO - Este trabalho foi conduzido para se avaliarem produtividade e as características morfológicas de cinco híbridos de milho Pioneer: superprecoce P32R21, os precoces P30R07, P3041, P30F33 e o semiprecoce P30F80, em cinco estádios de maturação. O delineamento utilizado foi de blocos ao acaso, com cinco tratamentos e quatro repetições. A colheita das amostras dos híbridos de milho foi adotada estimando-se cinco estádios de maturidade da planta: 30, 34, 38, 42 e 46\% de matéria seca. Por ocasião da colheita, no primeiro estádio de maturação, foram tomados alguns parâmetros para avaliação, como altura da planta, altura inserção de espiga, peso da planta, diâmetro de colmo e número médio de espigas. Para cada estádio de maturação, procedeu-se à separação de colmo + bainha, lâmina foliar, grão, sabugo e palha. Os híbridos superprecoce P32R21 e o precoce P3041 apresentaram maiores peso, diâmetro de colmo e altura de planta. As produções de matéria seca (MS), massa verde, grãos, lâmina foliar e colmo + bainha, expressas em toneladas/ha, diferiram entre os híbridos avaliados e houve efeito de dias pós-plantio (DPP). O aumento na produção de MS verificado com o avanço do estádio de maturidade dos híbridos foi correlacionado positivamente com o aumento da produção de grãos $\left(\mathrm{R}^{2}=64,3 \%\right)$. A produção de MS correlacionou-se positivamente com a percentagem de espiga $\left(\mathrm{R}^{2}=56,0 \%\right)$ e negativamente $\left(\mathrm{R}^{2}=-56,7 \%\right)$ com a percentagem de colmo + bainha (em relação a planta inteira).
\end{abstract}

Palavras-chave: colmo, espiga, grãos, lâmina foliar, matéria seca, milho

\section{Evaluation of Five Corn Hybrids (Zea mays, L.) at Different Maturity Stages. 1. Productivity, Morphologic Traits and Correlations}

ABSTRACT - This study was conducted to evaluate productivity and morphologic traits of five hybrids of Pioneer corn: P32R21, P30R07, P3041, P30F33 and P30F80 at different maturitystages. The treatments were used in plots of $7 \mathrm{x} 8 \mathrm{~m}$ in a randomized block design, with four replicates. The samples collected, of corn hybrid, were adopted trying to estimate phases of maturity of the plant $(30,34,38,42$ and $46 \%$ of dry matter [DM]). In the first maturation stage, some parameters (plant height, the ear of the corn insertion height, plant weight, stem diameter, number medium of ears of the corn) were evaluated, at harvest. For each maturation stage, was done separation of stem + sheath, leaf lamina, grain, cob and straw. The hybrid P32R21 and P3041 presented shown weight, diameter stem and plant height. Dry matter (DM) yield, green material, grain, leaf lamina, and stem + sheath, expound t/ha at hybrids were different and presented significance at days after seeding (DAS). The increase the productivity DM verify with the advanced the maturity stage hybrids, correlations positively with increase the production grain $\left(\mathrm{R}^{2}=64.3 \%\right)$. Too the production DM correlations positively with concentration ear $\left(\mathrm{R}^{2}=56.0 \%\right)$ and negatively $\left(\mathrm{R}^{2}=-56.7 \%\right)$ with the concentration stem + sheath (in relation a whole plant).

Key Words: corn, dry matter, ear, grain, leaf lamina, stem

\section{Introdução}

Ferreira (1990a) destacou que, para produzir silagem de milho de boa qualidade, várias recomendações técnicas devem ser atendidas, como a colheita do milho no estádio adequado de maturidade. Este procedimento é importante para uma maior produção de silagem de alto valor nutritivo, obtida ao menor custo possível. Segundo Demarquilly (1994), o estádio ótimo de colheita registrado na literatura é quando a quantidade de MS/ha é máxima e isto ocorre quando o grão atinge seu estádio farináceo-duro com teor de MS, variando de 33 a 35.

Lavezzo et al. (1997), ao avaliarem híbridos de milho em quatro estádios de maturidade: ML (milho com grãos no ponto leitoso), MP (milho com grãos no

1 Projeto financiado pela PIONEER SEMENTES, e parceria FUNDAÇÃO ABC

2 Parte da Dissertação de Mestrado apresentada pelo primeiro autor.

3 Médico - Veterinário, mestre em Produção Animal - PPZ/UEM. E.mail: jbeleze@hotmail.com

4 Professores do PPZ/ DZO/UEM. Av. Colombo, 5790 - 87020-900, Maringá - PR; Bolsista do CNPq. E.mail: Imzeoula@uem.br

5 Estudante de graduação em Zootecnia - DZO/ UEM - Bolsista de Iniciação Científica/ CNPq

6 Estudante de doutorado em Melhoramento Genético - PPZ/UEM. 
ponto pamonha), MF (milho com grãos no ponto farináceo) e MSD (milho com grãos no ponto semiduro), encontraram valor médio de 32,2 toneladas de matéria verde/ha, bem aquém das produções de 48,1 a 55,9 t/ha registradas por Evangelista et al (1982) e Valente et al. (1984). No entanto, deve-se considerar que a densidade do plantio adotada foi menor que a encontrada na literatura. Em relação à produção MS kg/ha, houve diferenças $(\mathrm{P}<0,05)$ entre os estádios de maturidade, sendo maiores para o MSD (9896 kg/ha) e MF (9866 kg/ha), seguido pelo MP ( $8736 \mathrm{~kg} / \mathrm{ha})$ e ML (7460 kg/ha).

Embora, a seleção de híbridos para produção de silagem de milho tenha sido baseada em produção de grãos e de matéria seca total, outros componentes da planta como: sabugo, colmo, folhas e palhas, não têm sido devidamente avaliados. Deste modo, uma considerável variabilidade entre híbridos de milho pode existir, quanto ao valor nutritivo, já que, nem sempre a maior proporção de grãos na forragem confere uma melhor qualidade à silagem (Caldwell \& Perry, 1971, Chamberlain et al., 1971, Johnson et al., 1985, Nussio, 1991, Demarquilly, 1994, Barrière et al., 1997, Mayombo et al., 1997). Segundo esses autores, a qualidade do grão e da fração fibrosa (caule, folhas, sabugo e palhas), combinada com o percentual de cada uma dessas partes na planta, é o que determina o valor nutritivo do material ensilado.

Flaresso et al. (2000) avaliaram cultivares de milho e sorgo e observaram que o ciclo das plantas, do plantio à colheita, foi de 120 dias para os mais tardios (XL-678 e AG-1051), próximo de 110 dias para os intermediários (XL-660, AG-519, P-3232 e AG-5011) e próximo a 100 dias para os mais precoces (C-806, AG-122, C-805, C-901, P-3069 e XL330). Nos cultivares de milho, houve tendência dos materiais mais tardios apresentarem maior altura que os mais precoces, enquanto que, em relação ao número de espigas por planta, observou-se igualdade, com valores próximos a um. Com relação às frações das plantas de milho, os materiais mais precoces apresentaram em torno de $30 \%$ de colmo em sua composição, contra $35 \%$ de materiais mais tardios e mais altos. No que diz respeito à participação de folhas observou-se valores em torno de $18,0 \%$. A proporção de espiga, componente mais importante para produção de silagem de alta energia, destacouse nos precoces variando de 47,0 a 42,4\%, nos tardios de 41,4 a $38,6 \%$. Para palha, os autores encontraram uma variação em torno de $7,7 \%$ para o cultivar tardio e de $11,8 \%$ para o cultivar precoce.

Este trabalho foi conduzido com o objetivo de avaliar os híbridos de milho (Zea mays, L.), de diferentes ciclos e estádios de maturação, quanto à produtividade e características morfológicas estruturais das plantas, para produção de silagem.

\section{Material e Métodos}

O plantio dos híbridos de milho Pioneer foi realizado na fazenda experimental "Capão Alto", pertencente à Fundação ABC, formada pelas Cooperativas Arapoti Ltda, Agropecuária Batavo Ltda e Sociedade Cooperativa Castrolanda, localizada no município de Castro, região sul do Estado do Paraná.

O plantio dos híbridos foi realizado em outubro de 1999 e as colheitas das amostras foram iniciadas em fevereiro de 2000, prolongando-se até o final de março de 2000.

O estabelecimento da cultura foi realizado em uma área plana de solo Latossólico vermelho amarelo. A análise do solo revelou as seguintes características: pH 5,1; P- $96 \mathrm{mg} / \mathrm{dm}^{3} ; \mathrm{Al}^{+++}-1 \mathrm{mg} / \mathrm{dm}^{3} ; \mathrm{K}-3,4 \mathrm{cmol} /$ $\mathrm{dm}^{3} ; \mathrm{Ca}^{++}-33 \mathrm{cmol} / \mathrm{dm}^{3} ; \mathrm{H}^{+}+\mathrm{Al}^{+++}-58 \mathrm{mg} / \mathrm{dm}^{3}$; $\mathrm{Mg}-17 \mathrm{cmol} / \mathrm{dm}^{3}$ e matéria orgânica- $46 \mathrm{mg} / \mathrm{dm}^{3}$.

Para o estabelecimento da cultura de milho, a área foi arada e posteriormente gradeada para destorroamento, nivelamento e abertura dos sulcos. Por ocasião da semeadura, em sulcos espaçados de $80 \mathrm{~cm}$, foi aplicado adubo correspondente a $150 \mathrm{~kg} / \mathrm{ha}$, da fórmula 15-30-0 (N-P-K) e adubação orgânica com esterco bovino 30.000 Litros/ha. Realizou-se também uma adubação em cobertura com $250 \mathrm{~kg} / \mathrm{ha}$, da fórmula 25-0-5 (N-P-K).

Foram avaliados cinco cultivares de milho híbrido Pioneer: superprecoce 32R21 (P32R21), precoce 30R07 (P30R07), precoce 3041 (P3041), precoce 30F33 (P30F33) e semiprecoce 30F80 (P30F80). O delineamento experimental utilizado foi de blocos ao acaso, com cinco tratamentos e quatro repetições.

A colheita das amostras dos híbridos de milho foi adotada tentando obedecer cinco estádios de maturação da planta: 30, 34, 38, 42 e 46\% de MS, totalizando 100 amostras da planta inteira (cinco estádios de maturação, cinco híbridos e quatro repetições). Com a finalidade de se alcançarem os cinco estádios de maturação, observou-se o dia pós-plantio (DPP), que correspondeu ao dia em que as amostras de cada híbrido foram colhidas no campo, obedecendo uma ordem cronológica (ciclo de pendoamento de 
cada híbrido), monitoramento da consistência do grão nas plantas da bordadura e a utilização de dados referentes à MS dos mesmos híbridos, plantados no mesmo período, mas em ano anterior.

A parcela experimental foi constituída de 11 linhas de sete metros de comprimento e com espaçamento de $80 \mathrm{~cm}$, totalizando oito metros de largura, portanto, a área de cada parcela utilizada correspondeu a $61,6 \mathrm{~m}^{2}$. Foi considerada uma área útil de $36 \mathrm{~m}^{2}$ em cada parcela, sendo que duas linhas laterais e hum metro das duas extremidades foram consideradas como bordaduras, portanto, as amostras foram obtidas das nove linhas restantes, fazendose uso de toda parcela experimental.

Em todos os estádios de maturação, foram colhidas três plantas/linha/parcela, totalizando 27 plantas amostradas/parcela (9 linhas na parcela). A colheita foi precedida de sorteio, desprezando-se plantas fora do padrão (outlier $=2$ plantas/cova); preocupou-se em não retirar plantas seguidamente, para evitar possíveis espaços (clarões) entre plantas, que pudessem também conduzir a um efeito competitivo entre elas. Das 27 plantas colhidas, uma foi utilizada para amostra de planta inteira, e as demais, para amostras de colmo + bainha, lâmina foliar e grão, em cada estádio de maturação. Depois de corte realizado a $45 \mathrm{~cm}$ do solo, com foice, todas as plantas da mesma parcela eram agrupadas, identificadas e transportadas para um local apropriado.

Por ocasião da primeira colheita, no primeiro estádio de maturação, foi avaliada a altura da planta até o início da inserção da folha bandeira, altura de espiga, número de espigas e diâmetro de colmo. A altura da planta e altura de inserção da espiga obtida a partir do solo foram medidas com uso de uma régua graduada e o diâmetro de colmo foi obtido com uso de um paquímetro.

Para cada estádio de maturação, procedeu-se à pesagem da massa verde de cada planta colhida, individualmente e, posteriormente, foi feita a separação de colmo + bainha, lâmina foliar, grão, sabugo e palha para pesagem destes.

Após a pesagem, todo o material colhido foi triturado em tamanho de aproximadamente $2 \mathrm{~cm}$ por meio de picadeira de forragens, com exceção do grão. Foi realizado a pré-secagem da fração verde e determinou-se a porcentagem de matéria seca (MS\%), das frações: planta inteira, grãos, lâmina foliar e colmo + bainha, segundo Silva (1998).

Procedeu-se às análise exploratórias dos dados e observou-se que para as variáveis: teores de matéria seca e peso de colmo kg/ha, não apresentaram distribuição normal $(\mathrm{P}<0,01)$. Então, admitiu-se uma distribuição gama para o erro em um Modelo Linear Generalizado (GLIM 4.0), como descrito por Nelder \& Wedderburn (1972), enquanto aquelas variáveis que se distribuíram normalmente em torno da média, as análises estatísticas, foram realizadas pelo aplicativo SAS 8.01.

\section{Resultados e Discussão}

Com relação à altura da planta, o híbrido superprecoce P32R21 apresentou o maior porte 2,56 metros $(\mathrm{m})$, diferindo $(\mathrm{P}<0,05)$ dos demais híbridos, seguido pelo híbrido precoce P3041 com 2,32 m (Tabela 1). Estes resultados contrariam aqueles observados por Flaresso et al. (2000), que observaram maior tendência na altura de plantas nos cultivares de milho mais tardios, em relação aos mais precoces.

O híbrido precoce $\mathrm{P} 3041$ apresentou a maior altura $(\mathrm{P}<0,05)$ de inserção da espiga de 1,34 m e o P30R07 a menor altura, de $1,06 \mathrm{~m}$ e estes diferiram $(\mathrm{P}<0,05)$ dos demais híbridos, que não diferiram entre si, com alturas de inserção da espiga de 1,26, 1,24, e 1,22 m, respectivamente, para o P30F80, P30F33 e P32R21.

$\mathrm{O}$ peso das plantas e o diâmetro de colmo diferiram $(\mathrm{P}<0,05)$ entre os híbridos e variaram de 0,712 a $0,925 \mathrm{~kg}$ e de 21,2 a 23,3 mm. De modo geral, os híbridos superprecoce P32R21 $(0,925 \mathrm{~kg})$ e o precoce P3041 (0,920 kg), que apresentaram maior peso, também apresentaram maior diâmetro de colmo, respectivamente, 23,3 e 23,0 mm, e o híbrido precoce P30R07 apresentou o menor peso da planta $(0,712 \mathrm{~kg})$ e o menor diâmetro de colmo $(21,2 \mathrm{~mm})$.

Roth et al. (1970), trabalhando com híbridos de milho, não encontraram correlação entre a proporção de grãos e a produção total de matéria seca (MS). Os autores afirmaram que, para a maximização desta produção, deveria haver máximo desenvolvimento de todas as porções estruturais da planta, sendo a altura e o diâmetro de colmo fortemente correlacionados com a produção de matéria seca.

Para teores de MS observados por ocasião das colheitas, após a análise de regressão verificou-se comportamento cúbico $(\mathrm{P}<0,05)$ em função dos dias pós plantio (DPP). Este comportamento, segundo Lopes \& Maestri (1981), é explicável devido às transformações governadas tanto pelas condições internas de crescimento da planta (composição morfológica e translocação de nutrientes), como pe- 
Tabela 1 - Altura das plantas (m), altura de inserção da espiga (m), peso de plantas (kg), diâmetro de colmo (mm) e espiga por planta ( $\left.\mathrm{n}^{\circ}\right)$ de diferentes híbridos de milho, no momento da primeira colheita

Table 1 - Plant height $(\mathrm{m})$, ear insertion height of ear $(\mathrm{m})$, plant weight $(\mathrm{kg})$, stem diameter $(\mathrm{mm})$ and number of ears of the corn per plant $\left(n^{\circ}\right)$ of different corn hybrids, at the moment of first harvest

\begin{tabular}{|c|c|c|c|c|c|}
\hline $\begin{array}{l}\text { Híbrido de milho } \\
\text { Hybrid corn }\end{array}$ & $\begin{array}{l}\text { Altura }(\mathrm{m}) \\
\text { Heigth }(\mathrm{m})\end{array}$ & $\begin{array}{c}\text { Altura de inserção espiga }(\mathrm{m}) \\
\text { Ear insertion heigth }(\mathrm{m})\end{array}$ & $\begin{array}{l}\text { Peso da planta }(\mathrm{kg}) \\
\text { Plant weight }(\mathrm{kg})\end{array}$ & $\begin{array}{l}\text { Diâmetro de colmo }(\mathrm{mm}) \\
\text { Stem diameter }(\mathrm{mm})\end{array}$ & $\begin{array}{c}\text { Espiga }\left(\mathrm{n}^{\circ}\right) \\
\operatorname{Ear}(n .)\end{array}$ \\
\hline P32R21 & $2,56 \mathrm{a}$ & $1,22 \mathrm{~b}$ & $0,925 \mathrm{a}$ & 23,3 a & 1 \\
\hline P30R07 & $2,23 \mathrm{c}$ & $1,06 \mathrm{c}$ & $0,712 \mathrm{~d}$ & $21,2 \mathrm{~d}$ & 1 \\
\hline P3041 & $2,32 \mathrm{~b}$ & $1,34 \mathrm{a}$ & $0,920 \mathrm{ab}$ & $23,0 \mathrm{ab}$ & 1 \\
\hline P30F33 & $2,23 \mathrm{c}$ & $1,24 \mathrm{~b}$ & $0,874 \mathrm{bc}$ & $22,0 \mathrm{~cd}$ & 1 \\
\hline P30F80 & $2,27 \mathrm{c}$ & $1,26 \mathrm{~b}$ & $0,869 \mathrm{c}$ & $22,2 \mathrm{bc}$ & 1 \\
\hline CV (\%) & 5,12 & 7,38 & 15,21 & 10,81 & \\
\hline
\end{tabular}

Médias, na coluna, seguidas de letras diferentes, diferem entre si $(P<0,05)$ pelo teste Tukey.

Means, within a collumn, followed by different letters are different $(P<.05)$ by Tukey test.

las externas (temperatura e umidade). Os valores estimados para os teores de MS em função DPP $(\mathrm{P}<0,05)$ e as equações de regressão estão mostrados na Tabela 2. Entretanto, observa-se que os teores de MS obtidos para os diferentes híbridos diferem um pouco daqueles cinco estádios de maturação que se pretendia inicialmente.

O teor de MS considerado como uma faixa ideal para o processo de ensilagem da planta de milho, situa-se entre 30 a 35 \% (Demarquilly, 1994; Barrière et al., 1997). Para o híbrido superprecoce P32R21, esta faixa de variação de 30 a $35 \%$ de MS foi obtida entre $132(29,88 \%$ MS $)$ e 137 DPP $(34,51 \%$ MS $)$, que significou aumento de 0,93 unidades percentuais de MS/dia. Para o híbrido precoce P30R07, foi observado que aos 128 DPP, ocasião da primeira colheita, já se encontrava com teor de MS de $33,13 \%$ e aos 135 DPP, de 35,09\%, observando-se aumento de 0,28 unidades percentuais de MS/dia. O híbrido precoce P3041 atingiu teor de 29,88\% de MS aos 140 DPP e $34,81 \%$ de MS aos 145 DPP, que representou um aumento de 0,99 unidades percentuais de MS/dia. Para o híbrido precoce P30F33, verificou-se que a variação, nos teores de MS de 29,93\% a 34,35\%, que foi obtida entre 131 a 142 DPP, significou aumento de 0,40 unidades percentuais de MS/dia. O híbrido semiprecoce P30F80 atingiu teor de MS de 29,69\% aos 155 DPP e, aos 162 DPP, estava com $34,78 \%$ de MS, que representou aumento de 0,73 unidades percentuais de MS/dia.

Se for considerada maior amplitude para a variação nos teores de MS, de 28\% (grão no estádio leitoso/ pastoso) a $40 \%$ de MS (grão no estádio duro), verificaram-se aumentos na faixa de 0,50 a 0,68 unidades de MS/dia, para os cinco híbridos estudados. Demarquilly (1994), considerando o estádio de floração (14 a 16\% de MS) até o grão no estádio farináceo duro (30 a 35\% MS), verificou aumento de 0,35 unidades de MS/dia, para a região de Clermont - Ferrand (França).

Deve-se ressaltar que os teores de MS obtidos para os híbridos de milho Pioneer são provenientes dos híbridos cultivados no município de Castro, região sul do Estado do Paraná. Durante o período de colheita dos híbridos a campo, os dados meteorológicos sinalizaram média de umidade relativa do ar de $80 \%$ e temperatura de $26^{\circ} \mathrm{C}$. O ciclo vegetativo é determinado por unidades de calor. Em clima quente, a planta cresce rapidamente e exige menos tempo para chegar ao período de polinização ou embonecamento. Se o clima é frio, o período da emergência até à fase do embonecamento aumenta (Fundação Cargill, 1978). Segundo Cabon (1996), a genética e as relações com fatores do meio, especialmente a água e a temperatura, podem explicar as diferenças no comportamento da planta, quanto à composição química e ao crescimento.

Verificaram-se correlações significativas entre os teores de matéria seca nos diferentes estádios de maturação dos híbridos e os componentes estruturais da planta e seus pesos. As correlações apresentadas e discutidas no presente trabalho foram aquelas acima de $50 \%$ ou para $\mathrm{P}<0,01$. Os teores de MS correlacionaram negativamente com a produção de matéria verde em $t / h a\left(R^{2}=-85,91\right)$, com a percentagem de colmo+bainha $\left(R^{2}=-74,76 \%\right)$ e com a percentagem de lâmina foliar na planta inteira $\left(R^{2}=-69,58 \%\right)$. Por outro lado, observou-se correlações positivas entre os teores de MS e a produção de MS $\left(\mathrm{R}^{2}=60,11 \%\right)$, produção de grão $\mathrm{kg} / \mathrm{ha}\left(\mathrm{R}^{2}=73,23 \%\right)$, percentagem de espiga na planta inteira $\left(\mathrm{R}^{2}=78,74 \%\right)$ e percentagem de grão na planta inteira $\left(R^{2}=55,33 \%\right)$. Deste modo, ficou evidenciado que o aumento nos 
Tabela 2 - Valores estimados dos teores de matéria seca (MS) dos híbridos de milho, em função dos dias pós plantio (DPP), em cinco estádios de maturação

Table 2 - Estimated values of dry matter (DM), fresh forage as a function of age (days after seeding-DAS) at five maturity stages

Híbridos de milho

Corn hybrid

\begin{tabular}{|c|c|c|c|c|c|c|c|c|c|}
\hline \multicolumn{2}{|c|}{ P32R21 1} & \multicolumn{2}{|c|}{ P30R07 2} & \multicolumn{2}{|c|}{ P3041 3} & \multicolumn{2}{|c|}{ P30F33 ${ }^{4}$} & \multicolumn{2}{|c|}{$\mathrm{P} 30 \mathrm{~F} 80^{5}$} \\
\hline DPP & $\% \mathrm{MS}$ & DPP & $\% \mathrm{MS}$ & DPP & $\% \mathrm{MS}$ & DPP & $\% \mathrm{MS}$ & DPP & $\% \mathrm{MS}$ \\
\hline$D A S$ & $\% D M$ & $D A S$ & $\% D M$ & $D A S$ & $\% D M$ & $D A S$ & $\% D M$ & $D A S$ & $\% D M$ \\
\hline 125 & 25,85 & 128 & 33,13 & 127 & 26,11 & 129 & 29,17 & 135 & 20,74 \\
\hline 129 & 27,69 & 134 & 33,76 & 134 & 25,42 & 135 & 31,71 & 142 & 25,85 \\
\hline 135 & 32,62 & 141 & 39,90 & 141 & 30,80 & 142 & 35,35 & 151 & 28,37 \\
\hline 142 & 38,93 & 149 & 47,40 & 149 & 38,28 & 151 & 40,05 & 157 & 30,68 \\
\hline 151 & 39,27 & 156 & 48,27 & 156 & 40,46 & 157 & 42,54 & 164 & 37,26 \\
\hline
\end{tabular}

$1 \% \mathrm{MS}=7434-1789-126,1^{*} \mathrm{DPP}+0,9373^{*} \mathrm{DPP}^{2}-0,002305^{\star} \mathrm{DPP}^{3}$

$2 \% \mathrm{MS}=7434-158,5^{*} \mathrm{DPP}+1,125^{*} \mathrm{DPP}^{2}-0,002644^{*} \mathrm{DPP}^{3}$

$3 \% \mathrm{MS}=7434-684,4-143,1 \mathrm{DPP}+1,009^{*} \mathrm{DPP}^{2}-0,002355^{*} \mathrm{DPP}^{3}$

$4 \% \mathrm{MS}=7434-6502-19,91 \mathrm{DPP}+0,1432^{*} \mathrm{DPP}^{2}-0,0003342^{*} \mathrm{DPP}^{3}$

$5 \% \mathrm{MS}=7434-12711+106,7^{*} \mathrm{DPP}-0,7169^{*} \mathrm{DPP}^{2}+0,001609^{*} \mathrm{DPP}^{3}$

teores de matéria seca foi decorrente principalmente da percentagem de espiga, como já relatado por Demarquilly (1994) e da produção de grão. Ainda, verificou-se que, com o avanço da maturidade da planta, podem ocorrer diminuição ou aumentos nas concentrações dos componentes estruturais da planta.

Na Tabela 3, encontram-se os dados de produções em tonelada por hectare (t/ha) de matéria verde (MV), de matéria seca, de grãos e de lâmina foliar, para os diferentes híbridos $(\mathrm{P}<0,05)$.

As produções de MV variaram entre 42,31 t/ha a 47,93 t/ha, a menor produção foi observada para o híbrido precoce P30R07 e a maior para o precoce P30F33. O valor médio obtido de 44,98 t MV/ha fica aquém das produções de 52,90 a 55,90 t/ha e de 49,03 a 58,89 t/ha e próximo a de 48,10 t/ha registradas, respectivamente, por Valente et al. (1984), Denardin et al. (1991) e Evangelista et al. (1991). Há que considerar, no entanto, que a densidade adotada neste experimento foi de $50.000 \mathrm{mil} \mathrm{plantas} / \mathrm{ha}$, portanto, menor que a densidade populacional de 60.000 e 75.000 plantas/ha usadas, pelos autores supracitados.

A maior $(\mathrm{P}<0,05)$ produção média de $\mathrm{MS}$ em t/ha $(17,24)$ foi também a maior $(\mathrm{P}<0,05)$ produção média de MV em t/ha (47,93), observada para o híbrido precoce P30F33, em relação aos demais. Já as menores produções de MS em $\mathrm{t} /$ ha foram para os híbridos superprecoce P32R21 $(15,65)$, precoce P3041 $(15,14)$ e semiprecoce P30F80 (15,50), que não diferiram entre si.

Para a produção média de grãos em t/ha, considerando todo o período de colheita, os híbridos diferiram $(\mathrm{P}<0,05)$ entre si. $\mathrm{O}$ híbrido superprecoce
Tabela 3 - Produções médias (cinco estádios de maturidade) de matéria verde (MV), matéria seca (MS), de grãos e da lâmina foliar (100\% MS) dos diferentes híbridos de milho (t/ha)

Table 3 - Mean production (five maturity stage) green material (GM), dry matter (DM), grain, leaf lamina at different corn hybrid ( $t /$ ha)

\begin{tabular}{lcccc}
\hline $\begin{array}{l}\text { Híbrido } \\
\text { Hybrid }\end{array}$ & $\begin{array}{c}\text { MV } \\
\text { GM }\end{array}$ & $\begin{array}{c}\text { MS } \\
\text { DM }\end{array}$ & $\begin{array}{c}\text { Grãos } \\
\text { Grain }\end{array}$ & $\begin{array}{c}\text { Lâmina foliar } \\
\text { Leaf lamina }\end{array}$ \\
\hline P32R21 & $44,12 \mathrm{c}$ & $15,65 \mathrm{c}$ & $8,46 \mathrm{a}$ & $1,65 \mathrm{c}$ \\
P30R07 & $42,18 \mathrm{~d}$ & $16,37 \mathrm{~b}$ & $8,44 \mathrm{a}$ & $2,11 \mathrm{a}$ \\
P3041 & $45,82 \mathrm{~b}$ & $15,14 \mathrm{c}$ & $7,23 \mathrm{~b}$ & $1,97 \mathrm{~b}$ \\
P30F33 & $47,93 \mathrm{a}$ & $17,24 \mathrm{a}$ & $8,19 \mathrm{a}$ & $2,13 \mathrm{a}$ \\
P30F80 & $44,69 \mathrm{bc}$ & $15,50 \mathrm{c}$ & $6,85 \mathrm{~b}$ & $2,19 \mathrm{a}$ \\
\hline
\end{tabular}

Médias, na coluna, seguidas de letras diferentes diferem entre si $(\mathrm{P}<0,05)$ pelo teste Tukey.

Means, within a collumn, followed by different letters are different $(P<.05)$ by Tukey test.

P32R21 e os híbridos precoces P30R07 e P30F33 apresentaram as maiores $(\mathrm{P}<0,05)$ produções de grãos, com médias superiores a $8 \mathrm{t} / \mathrm{ha}$, que o precoce P3041 e o semiprecoce P30F80. Estes híbridos são aqueles apresentados pelo Guia de Produtos Pioneer, cuja finalidade de uso é a produção de grão e o superprecoce P32R21, além da produção de grão, é também indicado para silagem da planta inteira e silagem de grãos úmidos. O híbrido semiprecoce P30F80 e o híbrido precoce P3041 apresentaram os menores valores de produção de grãos de 6,85 e 7,23 t/ha, respectivamente.

As produções de grãos observadas são superiores a àquelas relatadas por Johnson et al. (1985) de 5,27, 5,69 e 5,27 t/ha, para os híbridos americanos Coker 77B, 
Sunbelt 1876 e Mcnair 508, por Penati (1995) que observou produções médias de grãos de 4,33 t/ha e por Morello et al. (1998) que registraram produções de 3,73 e 5,91 t/ha para os híbridos BR 106 e ZENECA 8501.

Para a produção de lâmina foliar, o híbrido semiprecoce P30F80 (2,19 t/ha) e os híbridos precoces P30F33 (2,13 t/ha) e P30R07 (2,11 t/ha) apresentaram as maiores produções $(\mathrm{P}<0,05)$. Já as menores produções de lâmina foliar de 1,65 t/ha e de 1,97 t/ha foram observadas para os híbridos superprecoce P32R21 e o precoce P3041. Estes resultados se assemelham com as observações de Souza (1989) que, ao avaliar cultivares de milho para silagem, relatou que cultivares mais precoces são potencialmente menos produtores em folhas, em relação aos tardios. Também Nussio (1991) ressalta que, enquanto os híbridos de ciclo normal têm a tendência de apresentar maior desenvolvimento vegetativo, com maior número de folhas de 10 a 12 , nos milhos precoces são encontradas, em média, 6 a 8 folhas, abaixo da espiga.
Para a produção de MV da planta inteira, observou-se efeito linear $(\mathrm{P}<0,01)$ dos híbridos de milho e DPP, (Tabela 4). Nota-se que, com o avanço do estádio de maturidade do milho, ocorre uma diminuição na produção de matéria verde em t/ha, visto que o teor de MS é aumentado e, conseqüentemente, o teor em água é diminuído.

A produção de $\mathrm{MV} / \mathrm{ha}$ apresentou correlação significativa e positiva com as produções de colmo/ha $\left(\mathrm{R}^{2}=91,08 \%\right)$, produção de folhas $/ \mathrm{ha}\left(\mathrm{R}^{2}=87,47 \%\right)$, produção de palha/ha $\left(\mathrm{R}^{2}=89,72 \%\right)$, e produção de sabugo/ha $\left(\mathrm{R}^{2}=75,21 \%\right)$. Por outro lado, correlacionou-se negativamente com as concentrações de grão $\left(\mathrm{R}^{2}=-83,98 \%\right)$ de folha $\left(\mathrm{R}^{2}=-80,41 \%\right)$ e de colmo $\left(R^{2}=-69,72 \%\right)$ na planta inteira.

Verificou-se comportamento linear $(\mathrm{P}<0,01)$, com exceção do híbrido superprecoce P32R21, que foi observado efeito quadrático (Tabela 4), em função de DPP. Assim, verifica-se aumento na produção de MS com o avanço de maturidade do milho, fato este registrado na literatura (Johnson et al., 1971; Johnson

Tabela 4 - Equações de regressão para produções de matéria verde (MV), matéria seca (MS), grãos (PG), lâmina foliar (PLF) e colmo + bainha (PCB) dos híbridos de milho, em função de dias pós plantio (DPP)

Table 4 - Regression equation at the production the green material (GM), dry matter (DM), grain (GP), lamina leaf (LL) and stem + sheath (SS) of corn hybrid at day after seeding (days)

\begin{tabular}{|c|c|c|}
\hline $\begin{array}{l}\text { Híbrido } \\
\text { Hybrid }\end{array}$ & $\begin{array}{c}\text { Equação de regressão } \\
\text { Regression equation }\end{array}$ & $\mathrm{r}$ \\
\hline P32R21 & $\mathrm{MV}=148354-764,14 * \mathrm{DPP}$ & 0,97 \\
\hline P30R07 & $\mathrm{MV}=79652,9-263,66 * \mathrm{DPP}$ & 0,90 \\
\hline P3041 & $\mathrm{MV}=143555-691,16 * \mathrm{DPP}$ & 0,96 \\
\hline P30F33 & $\mathrm{MV}=108844-426,58 * \mathrm{DPP}$ & 0,86 \\
\hline P30F80 & $\mathrm{MV}=118765-494,5^{*} \mathrm{DPP}$ & 0,94 \\
\hline P32R21 & $\mathrm{MS}=-150837+2447,11 * \mathrm{DPP}-8,95 * \mathrm{DPP}^{2}$ & 0,48 \\
\hline P30R07 & $\mathrm{MS}=-5172,44+152,15 * \mathrm{DPP}$ & 0,92 \\
\hline P3041 & $\mathrm{MS}=9077,41+42,85 * \mathrm{DPP}$ & 0,59 \\
\hline P30F33 & $\mathrm{MS}=5879,85+79,54 * \mathrm{DPP}$ & 0,59 \\
\hline P30F80 & $\mathrm{MS}=4833,36+71,24 * \mathrm{DPP}$ & 0,62 \\
\hline P32R21 & $\mathrm{PG}=2,075+0,00495^{*} \mathrm{DPP}$ & 0,50 \\
\hline P30R07 & $P G=-0,1015+0,065^{*} \mathrm{DPP}$ & 0,71 \\
\hline P3041 & $\mathrm{PG}=0,4763+0,052 * \mathrm{DPP}$ & 0,70 \\
\hline P30F33 & $\mathrm{PG}=0,5696+0,0613 * \mathrm{DPP}$ & 0,75 \\
\hline P30F80 & $\mathrm{PG}=-0,3042+0,0511 * \mathrm{DPP}$ & 0,25 \\
\hline P32R21 & $\mathrm{PLF}=2,983-0,018 * \mathrm{DPP}$ & 0,92 \\
\hline P30R07 & $\mathrm{PLF}=3,038-0,017 * \mathrm{DPP}$ & 0,98 \\
\hline P3041 & $\mathrm{PLF}=4,277-0,025 * \mathrm{DPP}$ & 0,98 \\
\hline P30F33 & $\mathrm{PLF}=3,167-0,016 * \mathrm{DPP}$ & 0,89 \\
\hline P30F80 & $\mathrm{PLF}=4,032-0,022 * \mathrm{DPP}$ & 0,90 \\
\hline P32R21 & $\mathrm{PCB}=-16.605+310,9 * \mathrm{DPP}-1,22 * \mathrm{DPP}^{2}$ & 0,88 \\
\hline P30R07 & $\mathrm{PCB}=-16.605+25.720-86,76 * \mathrm{DPP}+0,3096 * \mathrm{DPP}^{2}$ & 0,90 \\
\hline P3041 & $\mathrm{PCB}=-16.605+39.331-259,3 * \mathrm{DPP}+0,8574 * \mathrm{DPP}^{2}$ & 0,75 \\
\hline P30F33 & $\mathrm{PCB}=-16.605+72.362-715,6 * \mathrm{DPP}+2,42 * \mathrm{DPP}^{2}$ & 0,79 \\
\hline P30F80 & $\mathrm{PCB}=-16.605-10.453+413,5 * \mathrm{DPP}-1,395 * \mathrm{DPP}^{2}$ & 0,80 \\
\hline
\end{tabular}


et al., 1985; Nussio, 1991; Bezerra et al., 1993; Cabon, 1996; Lavezzo et al., 1997). No geral, as produções de MS obtidas neste estudo, embora sejam inferiores àquela de 19,50 a 20,40 t/ha, conseguida por Evangelista et al. (1982), são superiores aos valores de 9,34 t/ha, 8,99 t/ha e de 9,46 a 13,07 t/ha registrados por Obeid et al. (1985), Lavezzo et al. (1997) e Silva et al. (1994), respectivamente e igualando-se aos valores de 16,92 a 17,73 t/ha, documentados por Denardin et al. (1991).

O estádio ótimo de colheita registrado na literatura é quando a quantidade de MS/ha é máxima e isto ocorre quando o grão atinge seu estádio farináceoduro, com teores de MS, variando de 33 a $35 \%$. Nestas condições, obtêm-se boa qualidade na conservação e digestibilidade máxima de silagens em bovinos (Demarquilly, 1994). Ainda, a variação de 30 a $35 \%$ MS permite que haja uma boa compactação do material a ser ensilado e, também, permite eliminar o ar e diminuir a porosidade da silagem (Muck, 1988 e Muck et al., 1991). Portanto, considerando esta faixa de variação de 30 a 35\% de MS, o híbrido superprecoce P32R21 atingiu produção máxima de matéria seca, de $16,4 \mathrm{t} / \mathrm{ha}$ aos 135 DPP com $32,62 \%$ de MS. Para os demais híbridos o máximo da produção de MS/ha foi observado com teores de MS mais elevado. Os híbridos precoces P30R07 e P3041, para esta mesma faixa de 30 a $35 \%$ de MS, observou-se a mesma produção máxima de MS de 15,3 t/ha, porém com diferença de dez DPP entre os híbridos, respectivamente, 135 e 145 DPP e ambos com teores de MS em torno de $34,60 \%$. Para o híbrido precoce P30F33 e o semiprecoce $\mathrm{P} 30 \mathrm{~F} 80$, a produção máxima de MS foi de $17,1 \mathrm{t} /$ ha e $16,4 \mathrm{t} / \mathrm{ha}$, respectivamente, atingida aos 141 DPP e 162 DPP e teor de MS, em ambos, de 34,80\%.

Constatou-se, por meio dos estudos de correlação, que mais de $60,0 \%$ da produção de MS/ha foi devido à produção de grãos em $\mathrm{t} / \mathrm{ha}\left(\mathrm{R}^{2}=64,31 \%\right)$. Entretanto, foi observado correlações negativas, porém baixas, com as produções de colmo, de folhas de palhas e de sabugos em $\mathrm{t} / \mathrm{ha}$ (em média $\mathrm{R}^{2}$ inferior a $30 \%$ ). Ainda a produção de $\mathrm{MS}$ em t/ha foi correlacionada positivamente com a concentração de espiga $\left(R^{2}=56,00 \%\right)$ e negativamente com a concentração de colmo+bainha $\left(\mathrm{R}^{2}=-56,74 \%\right)$ quando expressa na MS da planta inteira.

Também, verificou-se efeito linear $(\mathrm{P}<0,01)$ para a produção de grãos e DPP (Tabela 4), ou seja, com avanço da maturidade da planta houve aumento na produção de grãos. Segundo Nussio (1991), os híbri- dos superprecoces e precoces tendem a apresentar produção de grão por área superior aos híbridos normais ou tardios (tropicais). Nos híbridos precoces, nota-se tendência mais acentuada de translocação de sólidos solúveis dos órgãos da planta (folhas, caule, sabugo e palha) para a formação do grão. Ainda, o referido autor ressalta que os híbridos precoces apresentam-se com maior teor de matéria seca na planta, ao atingirem o ponto de maturidade ideal dos grãos para ensilagem. Isto irá garantir melhores condições de qualidade, não só em função da produção e proporção de grãos na matéria seca, mas também pelo maior teor de matéria seca do material, quando cortado no momento da ensilagem. Entretanto, deve-se ressaltar que os materiais de ciclo precoce são mais facilmente atingidos por qualquer fator do meio que limite o processo produtivo da planta do milho, como por exemplo, o déficit hídrico (Nussio, 1991; Penati, 1995; Almeida Filho, 1996).

Para produção de lâmina foliar ( $\mathrm{t} / \mathrm{ha}$ ) na matéria seca, observou-se efeito linear decrescente $(\mathrm{P}<0,05)$ em função de DPP (Tabela 4). Segundo os estudos de Demarquilly (1994), o valor energético de uma silagem de milho é resultado de dois fatores: o teor em grãos e a digestibilidade da parede celular. Portanto, o autor considera, além dos grãos, a fração colmo e folhas de grande importância e conclui que, se a quantidade de grãos entre duas variedades é próxima, é preferível optar pela variedade que apresenta mais folhas, resultando em aumento na quantidade de MS, com maior valor energético. Considerando apenas estes aspectos, produção de grãos e produção de lâmina foliar em t/ha, constatou-se que os híbridos superprecoce P32R21 e os precoces P30R07 e o P30F33 foram semelhantes quanto à produção de grãos, e os híbridos precoces P30R07 (2,11 t/ha) e o P30F33 (2,13 t/ha) apresentaram maior quantidade de folhas em $t / h a$, em relação ao superprecoceP32R21 (1,65 t/ha). Deste modo, o superprecoce P32R21 apresentaria menor produção de matéria seca (t/ha), como já observado na Tabela $3 \mathrm{e}$, conseqüentemente, a menor produção de energia em t/ha. Todavia, ao considerar a digestibilidade in vitro da matéria seca da planta inteira, para os híbridos avaliados, observou-se que as produções de MS digestível/ha para ambos os híbrido, o superprecoce P32R21 e o precoce P30F33, foi de 10,50 toneladas de MS digestível/ha, superando os precoces P30R07 (9,57 t/ha) e P3041 (9,81 t/ha) e o semiprecoce P30F80 (10,13 t/ha).

Houve efeito quadrático $(\mathrm{P}<0,01)$ do híbrido e de 
DPP para o peso de colmo + bainha (Tabela 4). O comportamento quadrático para a produção de colmo + bainha em função dos DPP pode ser explicado pelo efeito de concentração de nutrientes no colmo, que podem variar com o avanço do estádio vegetativo da planta e, ainda, através do processo de translocação de nutrientes entre as estruturas da planta de milho e a perda de água. Os pesos do colmo + bainha variaram entre 3,00 e 3,41 t/ha $(\mathrm{P}<0,05)$, sendo o menor valor observado para o híbrido superprecoce P32R21 e o maior para o semiprecoce $\mathrm{P} 30 \mathrm{~F} 80$, respectivamente. Estes pesos do colmo + bainha são superiores aos valores de 1,15 e 1,70 t/ha para os híbridos Agroceres AG 612 e Agroceres AG 122, relatados por Russo et al. (1994). Considerando a faixa de 30 a $35 \%$ de MS recomendados para o processo de ensilagem, verifica-se que os híbridos superprecoce P32R21 e o precoce P30R07 apresentaram as menores produções de colmo + bainha e também pequena variação de 3,00 a 3,06 t/ha. Já os híbridos semiprecoce P30F80 e o precoce P30F33 apresentaram produções de colmo + bainha que variaram, em média, de 3,52 a 3,13 t/ha, quando os teores de MS variaram de 30 a $35 \%$. Vale ressaltar que a fração colmo + bainha representa a porção menos digestível da planta.

Verificaram-se correlações significativas e positivas entre as produções de colmo + bainha (t/ha) e os componentes estruturais da planta e seus pesos: produção de matéria verde em $\mathrm{t} / \mathrm{ha}\left(\mathrm{R}^{2}=91,07 \%\right)$, produção da lâmina foliar $\left(\mathrm{R}^{2}=79,16 \%\right)$, produção de sabugo + palha $\left(\mathrm{R}^{2}=76,64 \%\right)$ e a percentagem de colmo + bainha na planta inteira $\left(\mathrm{R}^{2}=72,45 \%\right)$.

\section{Conclusões}

O aumento na produção de matéria seca em t/ha, verificado com o avanço do estádio de maturidade dos híbridos $(\mathrm{P}<0,01)$, foi devido principalmente ao aumento na produção de grãos em t/ha. Esta diferença na produção de MS situa-se entre 30 e $38 \%$ de MS, sendo os melhores estádios de colheita para os híbridos Pioneer avaliados.

A máxima produção de MS/ha foi de 17,24 t/ha, observada para o híbrido precoce P30F33, com aproximadamente $34,80 \%$ de MS (141 DPP).

O híbrido superprecoce P32R21 e os híbridos precoces P30R07 e P30F33 apresentaram as maiores produções de grãos, com médias superiores a $8 \mathrm{t} / \mathrm{ha}$. Os precoces P30R07 e P30F33 também apresentaram a maior produção de lâmina foliar (t/ha).
A maior produção de colmo + bainha foi verificada para o híbrido mais tardio, o semiprecoce P30F80, que, associado à menor produção de grãos, seria o menos recomendado para produção de silagem.

O melhor estádio de maturação para colheita de cada híbrido ficará a critério da composição químicobromatológica das diferentes frações da planta em relação ao avanço da maturidade, portanto aliando-se produção e qualidade.

\section{Agradecimento}

À Empresa Sementes Pioneer, pela oportunidade oferecida e pelo apoio para a realização deste trabalho.

À Fundação $\mathrm{ABC}$, pelo desenvolvimento do campo experimental.

\section{Literatura Citada}

ALMEIDA FILHO, S.L. Avaliação de cultivares de milho (Zea mays, L.) para silagem Viçosa, MG: Universidade Federal de Viçosa, 1996. 52p. Dissertação (Mestrado em Zootecnia) - Universidade Federal de Viçosa, 1996.

BARRIÈRE, Y.; ARGILLIER, O.; MICHALET-DOREAU, B. et al. Relevant traits, genetic variation and breeding strategies en early silage maize. Agronomie, v.17, p.395-411, 1997.

BEZERRA, E.S.; VON TIESENHAUSEN, I.M.E.V.; OLIVEIRA, A.I.G. et al. Valor nutricional das silagens de milho, milho associado com sorgo e rebrotas de sorgo. Revista Brasileira de Zootecnia, v.22, n.6, p.1045-1054, 1993.

CABON, G. Diversity of chemical composition evolutions of maize the weeks before harvesting Indicators of physiological stage. In: COLLOQUE MAÏS ENSILAGE, 1996, Nantes. Proceedings... Nantes: 1996. p.43-50.

CALDWELL, D.M.; PERRY, T.W. Relationships between stage of maturity of the corn plant time of harvest for corn silage and chemical composition.Journal of Dairy Science, v.54, n.4, p.533-536, 1971.

CHAMBERLAIN, C.C.; FRIBOURG, H.A.; BARTH, K.M. et al. Effect of maturity of corn silage at harvest on the performance of feeder heifers.Journal of Animal Science, v.33, n.1, p.161-166, 1971.

DEMARQUILLY, C. Facteurs de variation de la valeur nutritive du mais ensilage. INRA. Production Animal, v.7, n.3, p.177-189, 1994.

DENARDIN, R.B.N.; FÃO, V.M.; ROCHA, M.G. et al. Avaliação de cultivares e híbridos de milho, sorgo e milheto para produção de silagem. In: REUNIÃO ANUAL DA SOCIEDADE BRASILEIRA DE ZOOTECNIA, 28., 1991, João Pessoa. Anais... João Pessoa: Sociedade Brasileira de Zootecnia, 1991. p.12.

EVANGELISTA, A.R.; GALVÃO, J.D.; GARCIA, R. et al. Associação milho-soja: produção de massa verde e de matéria seca. Revista Ceres, v.29, n.162, p.155-163, 1982.

EVANGELISTA, A.R.; GARCIA, R.; OBEID, J.A. et al. Consórcio milho - soja: rendimento forrageiro, qualidade e valor nutritivo das silagens. Revista Brasileira de Zootecnia, v.20, n.6, p.578-584, 1991. 
FERREIRA, J.J. Aspectos vegetativos da planta de milho e momento da colheita para ensilagem. Informe Agropecuário, v.14, n.164, p.47-49, 1990a.

FUNDAÇÃO CARGILL. Melhoramento e produção do milho no Brasil. 1.ed. Piracicaba: Escola Superior de Agricultura "Luiz de Queiroz", 1978. 650p.

FLARESSO, J.A.; GROSS, C.D.; ALMEIDA, E.D. Cultivares de milho (Zea mays L.) e Sorgo (Sorghum bicolor (L.) Moench.) para ensilagem no alto Vale do Itajaí, Santa Catarina. Revista Brasileira de Zootecnia, v.29, n.6, p.1608-1615, 2000.

GUIA DE PRODUTOS - SEMENTES PIONEER. Produtos Pioneer na nutrição animal. 2000. 78p.

JOHNSON, R.R.; FARIA, V.P.; McCLURE, K.E. Effects of maturity on chemical composition and digestibility of bird resistant sorghum plants when fed to sheep as silages. Journal Animal Science, v.33, n.5, p.1102-1109, 1971.

JOHNSON JR, J.C.; MONSON, W.G.; PETLIGREW, W.T. Variation in nutritive value of corn hybrids for silage. Nutrition Reproduction International, v.32, n.4, p.953958, 1985

LAVEZZO, W.; LAVEZZO, O.E.N.M.; CAMPOS NETO, O. Estádio de desenvolvimento do milho. Efeito sobre produção, composição da planta e qualidade da silagem. Revista Brasileira de Zootecnia, v.26, n.4, p.675-682, 1997a.

LOPES, N.F.; MAESTRI, M. Crescimento, morfologia, partição de assimilados e produção de matéria seca do milho (Zea mays L.) cultivado em três densidades populacionais. Revista Ceres, v.28, n.157, p.268-288, 1981.

MAYOMBO, A.P.; DUFRASNE, I.; HORNICK, J.L. et al. Influencie du stade de maturité de la plante de may recolteé pour ensilage sur la composition, la digestibilité aparente, les caractéristiques de fermentation dans le rume et les performances zootechniques chez le taurillon à I'engraissement. Animal Zootech, v.46, p.43-55, 1997.

MORELLO, C.L.; PELÚZIO, J.M.; COELHO, R.M.S. et al. Comportamento de cultivares de milho no Estado do Tocantins - safra 1994/96. Revista Ceres, v.45, n.257, p.13-20, 1998.

MUCK, R.E. Factors influencing silage quality and they implications for management. Journal of Dairy Science, v.71, n.11, p.2992-3002, 1988.

MUCK, R.E.; PITT, R. E.; LEIBENSPERGER, R.Y. A model of aerobic fungal growth in silage.1. Microbial characteristics. Grass Forage Science, v.46, n.3, p.283-290, 1991.

NUSSIO, L. G. Cultura de milho para produção de silagem de alto valor alimentício. In: SIMPÓSIO SOBRE NUTRIÇÃO DE BOVINOS, 4., 1991, Piracicaba.Anais... Piracicaba: Escola Superior de Agricultura "Luiz de Queiroz", 1991. 302p.

NELDER, J.A.; WEDDERBURN, R.W.M. Generalized linear models. Journal of the Royal Statistical Society, v.135, p.370-384, 1972.
OBEID, J.A.; ZAGO, C.P.; GOMIDE, J.A. Qualidade e valor nutritivo de silagem consorciada de milho (Zea mays $L$.) com soja anual (Glycine Max. Merrill). Revista Brasileira de Zootecnia, v.14, n.4, p.439-446, 1985.

PENATI, M.C. Relação de alguns parâmetros agronômicos e bromatológicos de híbridos de milho (Zea mays $\mathbf{L}$.) com a produção, digestibilidade e teor de matéria seca na planta. Piracicaba: Escola Superior de Agricultura "Luiz de Queiroz", 1995.97p. Dissertação (Mestrado em Agronomia) - Escola Superior de Agricultura "Luiz de Queiroz".

PEREIRA, O.D.; OBEID, J.A.; GOMIDE, J.A.; QUEIROZ, A.C. Produtividade de uma variedade de milho (Zea mays $L$.) e de três variedades de sorgo (Sorghum bicolor L.) e o valor nutritivo de suas silagens. Revista Brasileira de Zootecnia, v.22, n.1, p.31-38, 1993.

POZAR, J.R.A.; ZAGO, C.P. Influência da densidade de plantio de milho (Zea mays, $L$.) sobre a produção de grãos e silagem, e alguns de seus componentes de produção e qualidade. Sementes Agroceres - Centro de Pesquisa de Capinópolis/SP, 1991.

ROTH, L.S.; MARTEN, G.C.; COMPTON, W.A. et al. Genetic variation of quality traits in maize (Zea mays, L) forage. Crop Science, v.10, p.365-367, 1970.

RUSSO, H.G.; HERLING, V.R. Avaliação da produtividade de 07 variedades de milho na região da alta paulista. In: REUNIÃO ANUAL DA SOCIEDADE BRASILEIRA DE ZOOTECNIA, 31., 1994, Maringá. Anais... Maringá: Sociedade Brasileira de Zootecnia, 1994. p.342.

SAS INSTITUTE. SAS user's guide for windows environment 8.01. Cary: 2000. 79p.

SILVA, A.W.L.; ALMEIDA, M.L.; MAFRA, A.L. et al. Avaliação de híbridos e variedades de milho para ensilagem. II Características químico - bromatológicas do material na colheita. In: REUNIÃO ANUAL DA SOCIEDADE BRASILEIRA DE ZOOTECNIA, 31., 1994, Maringá. Anais... Paraná: Sociedade Brasileira de Zootecnia, 1994. p.345.

SOUZA, S.N. Milho para silagem: considerações agronômicas. Agropecuária Catarinense, v.2, n.2, p.11-14, 1989.

VALENTE, J.O.; SILVA, J.F.C.; GOMIDE, J.A. Estudo de duas variedades de milho (Zea mays $L$ ), e de quatro variedades de sorgo para silagem. 1. Produção e composição do material ensilado e das silagens. Revista Brasileira de Zootecnia, v.13, n.1, p.67-73, 1984.
Recebido em: 28/02/02 Aceito em: 30/10/02 